\title{
Comparative Micro Structural Investigation of Al-SiC-Mg and Al-B4C-Mg Particulate Metal Matrix Composite
}

\author{
Paridhi Malhotra $^{1 *}$, Nishant K. Singh ${ }^{2}$, Ram K. Tyagi ${ }^{3}$, Basant Singh Sikarwar ${ }^{3}$ \\ ${ }^{1}$ Amity University, Noida 201313, India \\ ${ }^{2}$ Department of Mechanical Engineering, Hindustan College of Science and Technology, Mathura 281122, India \\ ${ }^{3}$ Department of Mechanical Engineering, Amity University, Noida 201313, India
}

Corresponding Author Email: paridhi.malhotra@student.amity.edu

https://doi.org/10.18280/acsm.440205

Received: 20 December 2019

Accepted: 16 February 2020

\section{Keywords:}

hybrid composite, stir casting, reinforcement, boron carbide, silicon carbide, magnesium

\begin{abstract}
For the first time, the comparative assessment of $\mathrm{Al}-\mathrm{SiC}-\mathrm{Mg}$ and $\mathrm{Al}-\mathrm{B} 4 \mathrm{C}-\mathrm{Mg}$ hybrid metal matrix composite is being explored. The primary objective of the present work is to compare different properties of reinforced A17075. Boron carbide and silicon carbide (available in powdered form) were mixed with the alloy in different percentages to check their effect along with magnesium present in powdered form. Boron carbide (also known as black diamond) was selected as it is highly robust and has good shielding properties against neutrons i.e. it absorbs them well. It can stabilize the ionizing radiations and is the third hardest known substance after diamond and cubic boron nitride. Silicon carbide was selected as it has high strength and hardness with good wear resistance properties. Magnesium is selected because it is the lightest of all the metals and has good heat dissipation and good damping capacity. Fabricated composite is lightweight and could find applications in the aircraft industry, automotive parts, and defense applications. Samples were prepared using the modified stir casting method. Samples were then collected from the die and after those mechanical properties were tested (tensile test and hardness test). SEM/EDS and XRD analyses were conducted to briefly study the microstructure and phase of the samples prepared. The recent research involves the novel objective of manufacturing hybrid composite of Al7075 and evaluation of its mechanical properties and surface morphography. The use of hybrid metal matrix composite enables fine-dimensional precision machining of micro-parts, opening up fresh possibilities for micro-components based on $\mathrm{Al}-\mathrm{SiC}-\mathrm{Mg}$ and $\mathrm{Al}-\mathrm{B}_{4} \mathrm{C}-\mathrm{Mg}$.
\end{abstract}

\section{INTRODUCTION}

Excellent mechanical and tribological properties make Aluminium metal matrix composite (AMMC) operated in various engineering applications fulfilling the growing needs of industrial requirements. Aluminium is one of the most commonly used metal matrix as it has low specific gravity compared to the other metals and is readily available in various alloy forms. Aluminium matrix can provide a route to noteworthy improvements in wear, hardness, strength and corrosion resistance [1]. For improvising the properties of materials various reinforcement materials are added such as $\mathrm{SiC}, \mathrm{B}_{4} \mathrm{C}, \mathrm{Al}_{2} \mathrm{O}_{3}$ etc. To overcome certain limitations nanocomposites of Aluminium are used by mixing it with some hard materials [2]. The reinforcement is present in various forms such as particulates, whiskers, and fibers. The reinforcement is supported and surrounded by the matrix material preserving its relative orientation. Chemical reaction amid the metal alloy and the reinforcement material, uniform distribution of the reinforcement is some of the important factors that need significant awareness during the preparation of composite. In the modern era, more than one reinforcement is added to obtain good properties of MMC. Deployment of Hard ceramic particles as reinforcements tends to increase the tensile strength, hardness and density of the composite [3]. For fundamental and practical reasons aluminium composites have gained enormous attention [4]. It was Evaluated by researchers that by enriching the reinforcement amount the impact energy of the composites also increases [5]. In comparison to single reinforced composites, composites with more than one reinforcement have better properties as they integrate the advantages of their constituent reinforcements [6]. The various grades of aluminium make it such a matrix which retrieves the huge type of nanoparticles by various methods and form metal matrix coalesce [7]. The hybrid composites offer greater compressive strength than the single massive alloy because of the inclusion of the reinforcement particles which are rigid in the matrix alloy [8]. Sun et al observed that the size of the particle cast an important effect on the Aluminium matrix composite. Mechanical behavior and the surface microstructure of the composite ameliorate with the size of the particles. The density of the composite decreases with permeability and collection of huge size particles and perceived high tensile and yield strength with the diminishing size of the particles.

Zinc is one of the major alloying elements present in the metal matrix alloy of Al7075 is an alloy having maximum strength, nearly good fatigue strength and relatively less resistance to corrosion $[9,10]$. It has perceived that the wear resistance increases notably by enhancing the wt.\% of boron carbide. All these properties can be improved by adding reinforcement of various particles. The major advantage of 
MMC's is its ability to be acclimated. Out of the numerous manufacturing methods stir casting for manufacturing metal matrix composites is one of the least expensive and commonly used processes [11]. The cost of the stir casting process is one third as compared to other manufacturing processes [12]. Rohit et al. [13] fabricated Mg metal matrix composite using a stir casting process with a varying weight percentage of the reinforcements and investigated numerous mechanical properties such as hardness and tensile strength. Alaneme et al. [14] aimed at producing aluminium hybrid composite using bamboo leaf ash and different weight percentages of silicon carbide and assessed microstructure character and various mechanical properties and observed that the tensile strength, hardness decreases with the increase of bamboo lash reinforcement. Manikandan et al. [15] analyzed hardness, compressive strength and wear resistance of the aluminium 6061 alloys with an increasing weight percentage of $\mathrm{MgO}$ reinforcement and found that the mechanical properties increase with increased wt.\% of reinforcement. Fibers are efficiently used as reinforcement because of their property of transferring strength which results in amplification of mechanical as well as physical properties [16]. In the coming time, industries manufacturing composites will be using more than one component as reinforcement in the production of composites [17]. The processing technique embraced for the fabrication of the metal matrix composites is dependent on the nature of both the matrix alloy and the reinforcement and influences the final properties of the MMC.

The present study aimed at evaluating the metal matrix alloy of Al-SiC-Mg and Al-B ${ }_{4} \mathrm{C}-\mathrm{Mg}$ containing $(5,10 \mathrm{wt} . \%)$ of $\mathrm{SiC}$ and $\mathrm{B}_{4} \mathrm{C}$ and $1 \mathrm{wt} \%$ of $\mathrm{Mg}$ keeping all other parameters constant. Two different hybrid metal matrix composites were used in the experiments. The composites were prepared using the process of stir casting. Moreover, mechanical properties such as hardness, tensile strength, and microstructure using SEM images are analyzed. The present study aimed at producing wear-resistant products using ultra-fine particulates and reducing the production cost.

\section{EXPERIMENTAL WORK}

\subsection{Material}

Aluminium alloy 7075 is selected as matrix material as it possesses high strength, high toughness and it is preferable in many engineering sectors [18]. Because of lower noise and low fuel utilization, aluminium matrix composites perceive a broader scope of acceptance in the transportation sector. When these composites are reinforced with ceramic particles, they are preferred for elevated temperature applications.

Nano-sized particles of Silicon carbide and boron carbide are being used as alloy reinforcement. $\mathrm{Al}-\mathrm{SiC}$ composites are keen interest sector for researchers because of the high strength, high specific modulus and excellent compatibility of $\mathrm{SiC}$ with $\mathrm{Al} . \mathrm{B}_{4} \mathrm{C}$ is selected as the reinforcement for aluminium matrix nanocomposites because of its low density and high hardness, high thermal stability than any other reinforcement Poor wettability is one of the major concerns during the fabrication of composites. Magnesium is included to enhance the wet ability. $\mathrm{Mg}$ has excellent interfacial bonding between the hard metal alloy and the soft backing [19]. The wt.\% of reinforcement of $\mathrm{SiC}$ and $\mathrm{B}_{4} \mathrm{C}$ with metal matrix phase is $0,5,10$. SiC particulate is heated beforehand at $800^{\circ} \mathrm{C}$ for 2 hours to refine the wet ability by eliminating the absorbed hydroxide and other gasses. The furnace temperature is raised to a temperature of about $1100^{\circ} \mathrm{C}$ to completely liquefy the matrix.

Mechanical stirring was accomplished at an average stirring speed of $350 \mathrm{rpm}$ for 30 minutes. The uniformity of the composite material is mainly influenced by the position of the stirrer [20]. The dimensions of the specimen are $125 \mathrm{~mm}$ in length and $18 \mathrm{~mm}$ in diameter. Table 1 indicates the chemical composition of the 7075 aluminium alloy. Table 2 represents the properties of reinforcement.

Compositions of mixtures of each composite formed are as follows:

1. Al7075 (100\%) SiC (0\%) Mg (0\%)

2. $\mathrm{Al} 7075-\mathrm{SiC}(5 \%)-\mathrm{Mg}(1 \%)$

3. Al7075- SiC (10\%)-Mg (1\%)

4. $\mathrm{Al} 7075-\mathrm{B}_{4} \mathrm{C}(5 \%)-\mathrm{Mg}(1 \%)$

5. $\mathrm{Al} 7075-\mathrm{B}_{4} \mathrm{C}(10 \%)-\mathrm{Mg}(1 \%)$

Table 1. The chemical composition of Al7075

\begin{tabular}{cccccc}
\hline Si & $\mathbf{Z n}$ & $\mathbf{M n}$ & $\mathbf{M g}$ & $\mathbf{C r}$ & Al \\
\hline 5.4 & 1.42 & 0.12 & 2.42 & 0.21 & Rest. \\
\hline
\end{tabular}

Table 2. The properties of the reinforcements

\begin{tabular}{ccc}
\hline Properties & SiC & B $_{\mathbf{4}} \mathbf{C}$ \\
\hline Density $\left(\mathrm{g} / \mathrm{cm}^{3}\right)$ & 3.21 & 2.52 \\
Elastic modulus $(\mathrm{GPa})$ & 430 & 450 \\
Hardness & 2480 & 2800 \\
Compressive strength $(\mathrm{MPa})$ & 2800 & 3000 \\
Thermal & 132 & 29 \\
conductivity $(\mathrm{W} / \mathrm{mK})$ & & \\
Sp.Thermal conductivity & 41.1 & 11.5 \\
\hline
\end{tabular}

\section{MECHANICAL PROPERTIES EVALUATION}

The suggested A17075-SiC-Mg / Al7075-B ${ }_{4} \mathrm{C}-\mathrm{Mg}$ MMC were generated by the modified stir casting method. AA7075 alloy was used as a $\mathrm{SiC} / \mathrm{B}_{4} \mathrm{C}$ matrix and $\mathrm{Mg}$ was used as reinforcement during the stirring phase. A batch of 218 grams of aluminum alloy was melted in a clay graphite crucible. It was further melted in the strength Induction furnace at the desired temperature of $1100^{\circ} \mathrm{C}$. In the meantime, $\mathrm{SiC} / \mathrm{B}_{4} \mathrm{C}$ and $\mathrm{Mg}$ nanopowder were heated in another crucible at a temperature of $800^{\circ} \mathrm{C}$ to eliminate moisture and the die was preheated to a temperature of $100^{\circ} \mathrm{C}$. The mixture was stirred uninterruptedly for 20-30 minutes at speed of $300 \mathrm{rpm}$. The melt temperature was preserved at $1125^{\circ} \mathrm{C}$ throughout the inclusion of the particulate.

\subsection{Hardness test}

The Vicker's hardness or the microhardness of the samples was measured at distinct positions at a load of $1 \mathrm{~kg}$ for a duration of $10 \mathrm{sec}$. The hardness test was accomplished using (Matsuzawa MMT-X) Vicker's hardness machine. The optical measurement system forms the basis. The indentations are large enough to maximize the measurement resolution. The diamond indenter was used. Figure 1 shows the sample of the workpiece. Table 3 shows the result of the hardness test. Figure 2 shows the graph depicting the hardness level of the given specimens. Table 4 shows the experimental and theoretical density of the nanocomposites. 
Table 3. Results of the hardness test

\begin{tabular}{cccccc}
\hline \multicolumn{7}{c}{ Results of hardness test of Al7075-SiC-Mg \& Al7075-B4C-Mg } \\
\hline & Al7075 & Al7075-5\%Sic-Mg & Al7075-10\%SiC-Mg & Al7075-5\% B4C-Mg & Al7075-10\% B4C-Mg \\
\hline 1 & 172.6 & 182.4 & 199.3 & 129.2 & 145.1 \\
2 & 173.2 & 184.3 & 205 & 130.6 & 146.3 \\
3 & 170.9 & 190.1 & 200.9 & 130.1 & 148 \\
4 & 180.6 & 179.9 & 204 & 131.8 & 148.4 \\
5 & 176.2 & 178.2 & 203.6 & 128.9 & 147 \\
\hline Avg. hardness & $\mathbf{1 7 5}$ & $\mathbf{1 8 3}$ & $\mathbf{2 0 3}$ & $\mathbf{1 3 0}$ & $\mathbf{1 4 7}$ \\
\hline Std deviation & $\mathbf{3 . 8 1 3}$ & $\mathbf{4 . 6 1 3}$ & $\mathbf{2 . 3 7 1 2 8 7}$ & $\mathbf{1 . 1 6 1}$ & $\mathbf{1 . 3 2 8}$ \\
\hline
\end{tabular}

Table 4. Results of the experimental and theoretical density of the nanocomposites.

\begin{tabular}{cccccc}
\hline \multicolumn{6}{c}{ Results of theoretical and experimental density Al7075-SiC-Mg and Al7075-B4C-Mg } \\
\hline & $\mathbf{A l 7 0 7 5}$ & $\mathbf{A l 7 0 7 5 - 5 \%}$ Sic-Mg & $\mathbf{A l 7 0 7 5 - 1 0 \% \text { SiC-Mg }}$ & $\mathbf{A l 7 0 7 5 - 5 \% B}$ - $\mathbf{C}-\mathbf{M g}$ & $\mathbf{A l 7 0 7 5 - 1 0 \% B}$ - $\mathbf{C}-\mathbf{M g}$ \\
\hline 1 & 2.81 & 3.18 & 3.012 & 2.46 & 2.035 \\
2 & 2.821 & 3.012 & 2.896 & 2.308 & 2.325 \\
3 & 2.765 & 2.99 & 2.951 & 2.222 & 2.68 \\
4 & 2.732 & 3.003 & 3.009 & 2.95 & 2.103 \\
\hline Average density & $\mathbf{2 . 7 8 2}$ & $\mathbf{3 . 0 4 6}$ & $\mathbf{2 . 9 6 7}$ & $\mathbf{2 . 4 8 5}$ & $\mathbf{2 . 2 8 6}$ \\
\hline Standard deviation & $\mathbf{0 . 4 1 2 0}$ & $\mathbf{0 . 0 8 9 4}$ & $\mathbf{0 . 0 5 5 0 3}$ & $\mathbf{0 . 3 2 5 2}$ & $\mathbf{0 . 2 9 0 5}$ \\
\hline Theoretical density & $\mathbf{2 . 8 1}$ & $\mathbf{3 . 1 6}$ & $\mathbf{3 . 2 1}$ & $\mathbf{2 . 5 2}$ & $\mathbf{2 . 4 8}$ \\
\hline Porosity (\%) & $\mathbf{2 . 4 2}$ & $\mathbf{3 . 8 1}$ & $\mathbf{6 . 3 2}$ & $\mathbf{3 . 7 5}$ & $\mathbf{5 . 6 6}$ \\
\hline
\end{tabular}

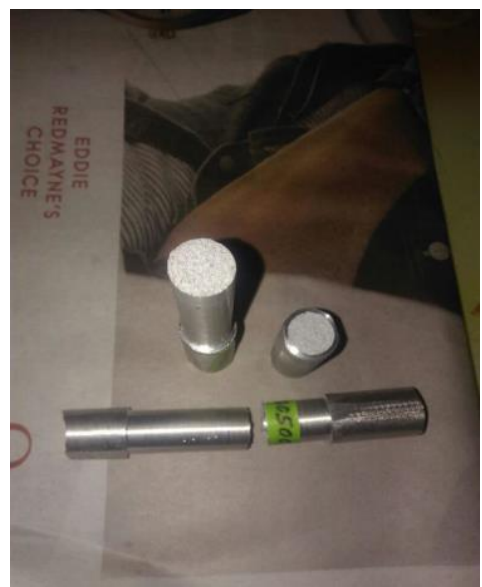

Figure 1. Sample of the workpiece

Vicker's Test

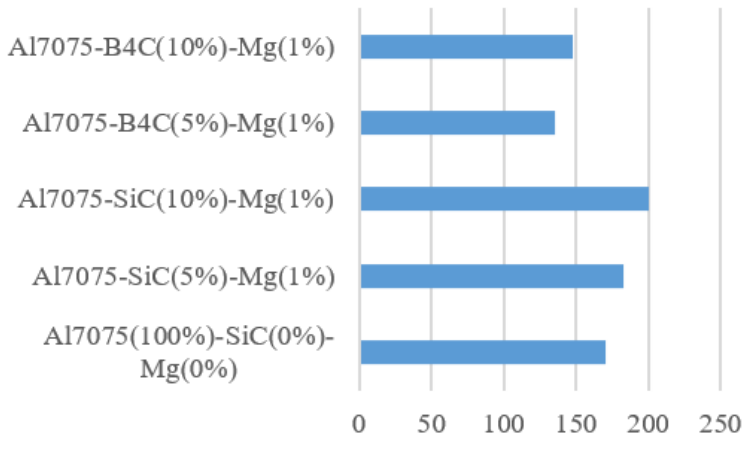

a Hardness in VHN

Figure 2. Graph depicting the hardness level of the given specimen

\subsection{Tensile test}

Tensile test specimens were prepared from the samples produced by the casting process. To have high accuracy, three samples were made from each specimen according to the ASTM standards. Figure 3 demonstrates the tensile test specimen of all sizes used for experiments. Figure 4 demonstrates the sample as per the ASTM standard. The outcome of the tensile test is shown in Table 5. Figure 5 demonstrates the graph showing the tensile strength of the samples into consideration.

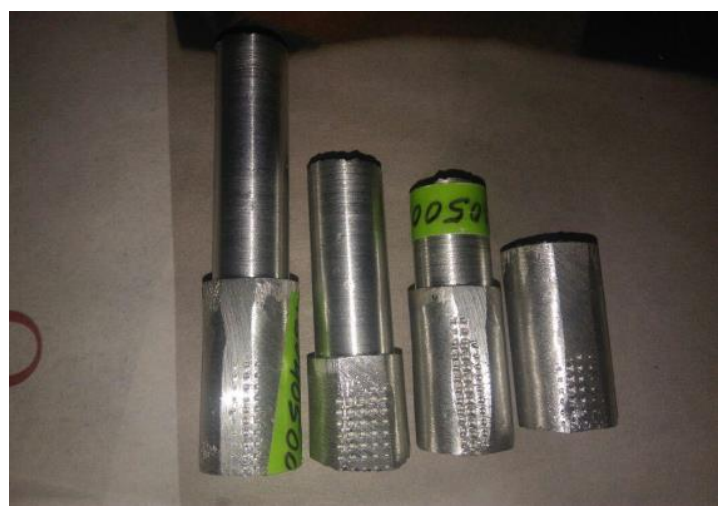

Figure 3. Tensile specimen with all the dimensions

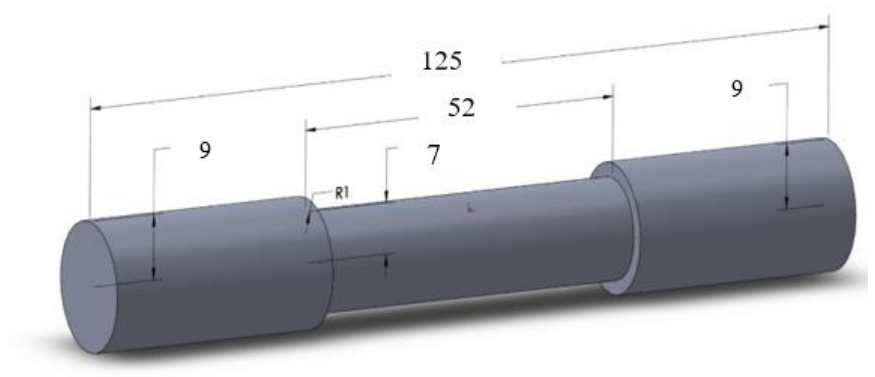

Figure 4. Sample as per ASTM standard 
Table 5. Results of tensile strength

\begin{tabular}{lll}
\hline 1 & $\mathrm{~A} 17075(100 \%) \mathrm{SiC}(0 \%) \mathrm{Mg}(0 \%)$ & $220 \mathrm{MPa}$ \\
\hline 2 & $\mathrm{~A} 17075-\mathrm{SiC}(5 \%)-\mathrm{Mg}(1 \%)$ & $231.2 \mathrm{MPa}$ \\
\hline 3 & $\mathrm{~A} 17075-\mathrm{SiC}(10 \%)-\mathrm{Mg}(1 \%)$ & $243.4 \mathrm{MPa}$ \\
\hline 4 & $\mathrm{~A} 17075-\mathrm{B}_{4} \mathrm{C}(5 \%)-\mathrm{Mg}(1 \%)$ & $212.5 \mathrm{MPa}$ \\
\hline 5 & $\mathrm{~A} 17075-\mathrm{B}_{4} \mathrm{C}(10 \%)-\mathrm{Mg}(1 \%)$ & $221.5 \mathrm{Mpa}$ \\
\hline
\end{tabular}

\subsection{Microstructure}

Figure 6 demonstrates the SEM image of A17075-5\% $\mathrm{B}_{4} \mathrm{C}$ $1 \% \mathrm{Mg}$. Splats can be seen, the white portion of the image shows that carbide particles have not been accomplished carefully even when stirring has been used during casting.

Figure 7 demonstrates the microscopic perspective of $\mathrm{Al} 7075-10 \% \mathrm{~B}_{4} \mathrm{C}-1 \% \mathrm{Mg}$. Peaks are noted due to incorrect cutting and grinding of the specimen. Dots are noted all over the ground.

Figure 8 illustrates the microscopic depiction of Al7075$5 \% \mathrm{SiC}-1 \% \mathrm{Mg}$. A few white regions are noticeable owing to carbide particles in layered shape. Dots are due to the $\mathrm{SiO}_{2}$ formation.

Figure 9 shows the SEM image of Al7075-10\%SiC-1\% Mg. In most cases, the layers are not so visible in SEM, but because the magnification is low, the layers of different materials are observed which reveal the presence of $\mathrm{Fe}, \mathrm{SiO}_{2}$ and $\mathrm{C}$.

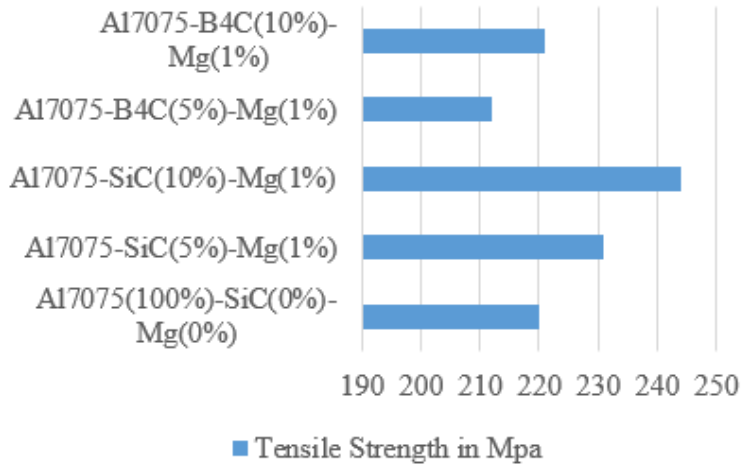

Figure 5. Graph depicting the tensile strength of the given specimens

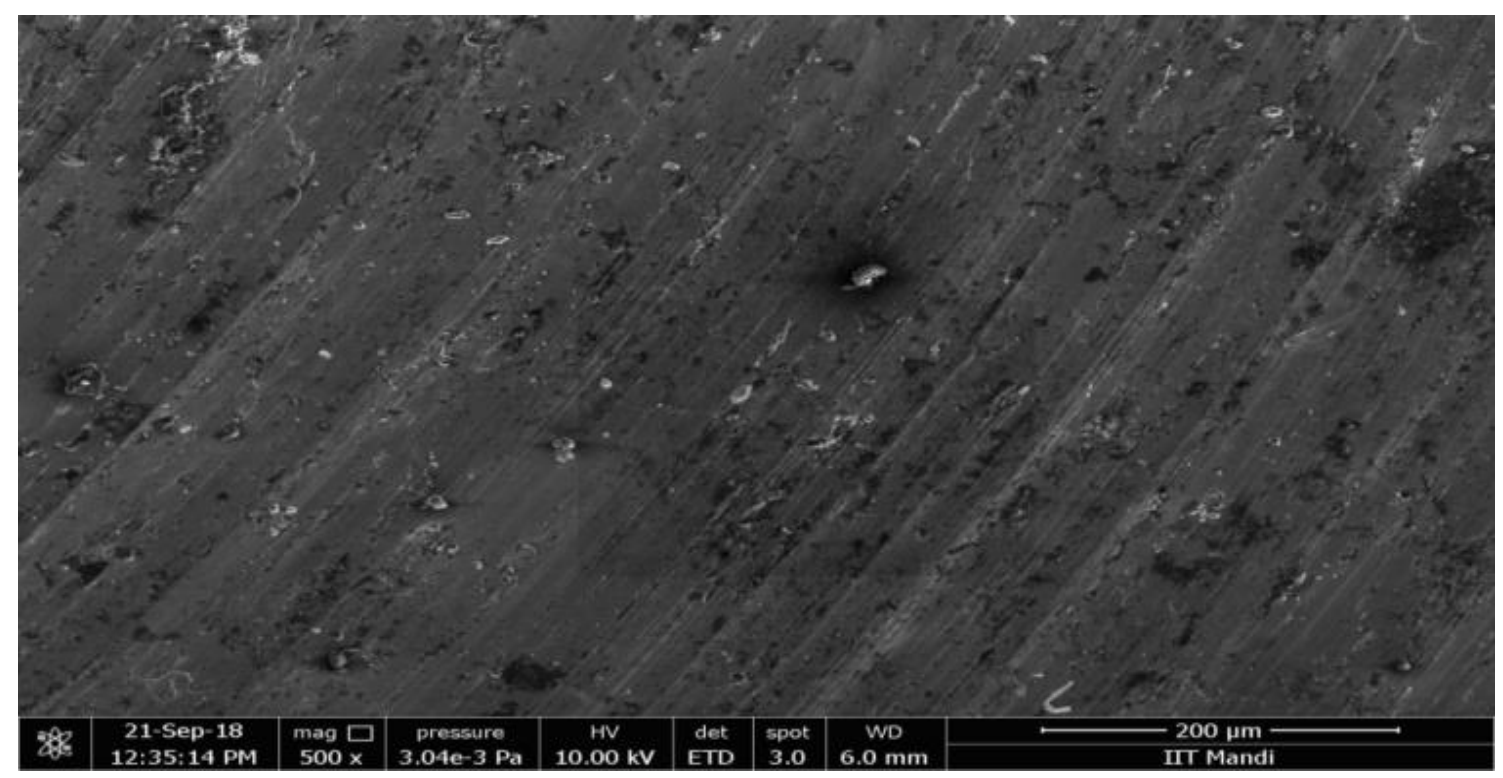

Figure 6. SEM image of $\mathrm{Al} 7075-(5 \%) \mathrm{B}_{4} \mathrm{C}-(1 \%) \mathrm{Mg}$

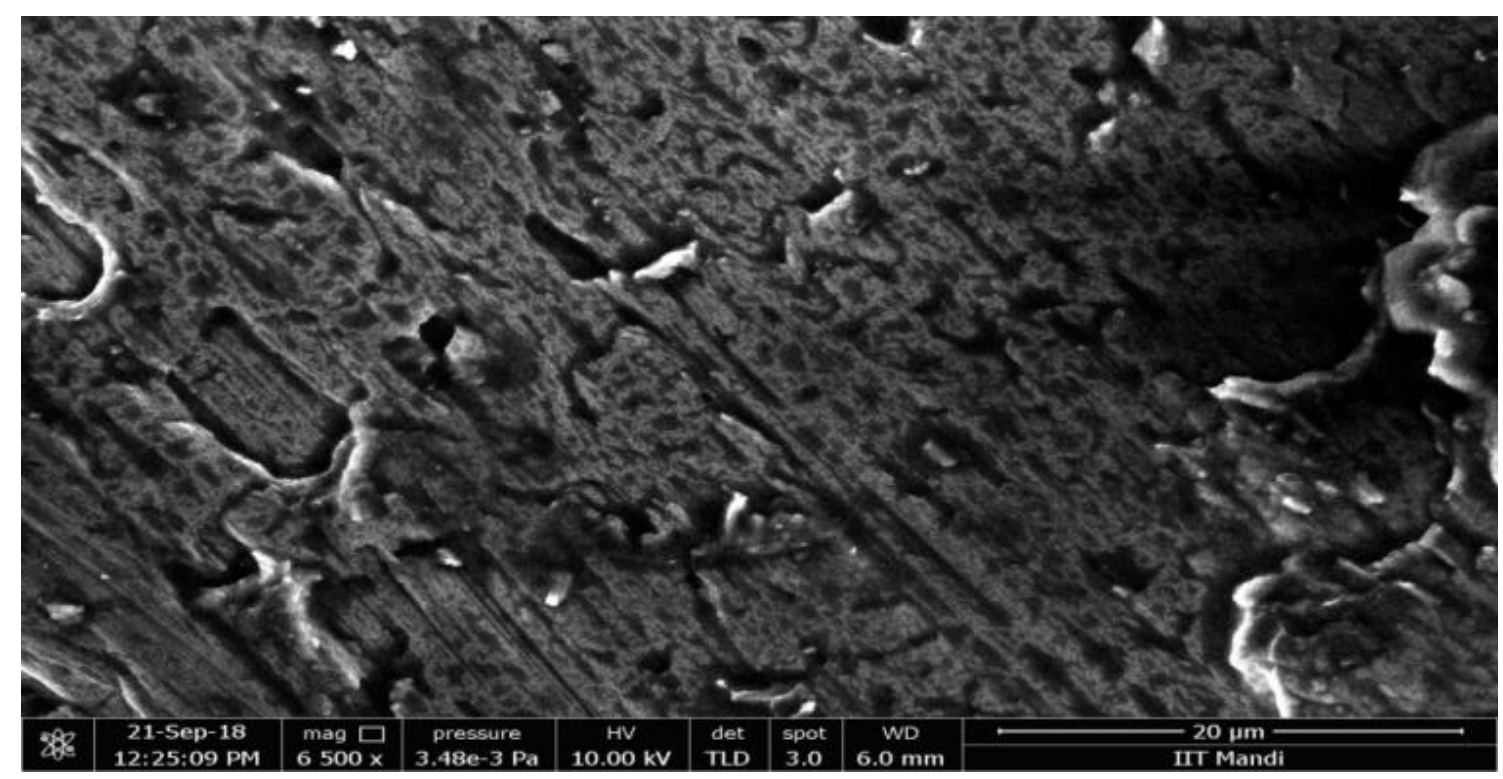

Figure 7. Microscopic view of Al7075-(10\%)B ${ }_{4} \mathrm{C}-(1 \%) \mathrm{Mg}$ 


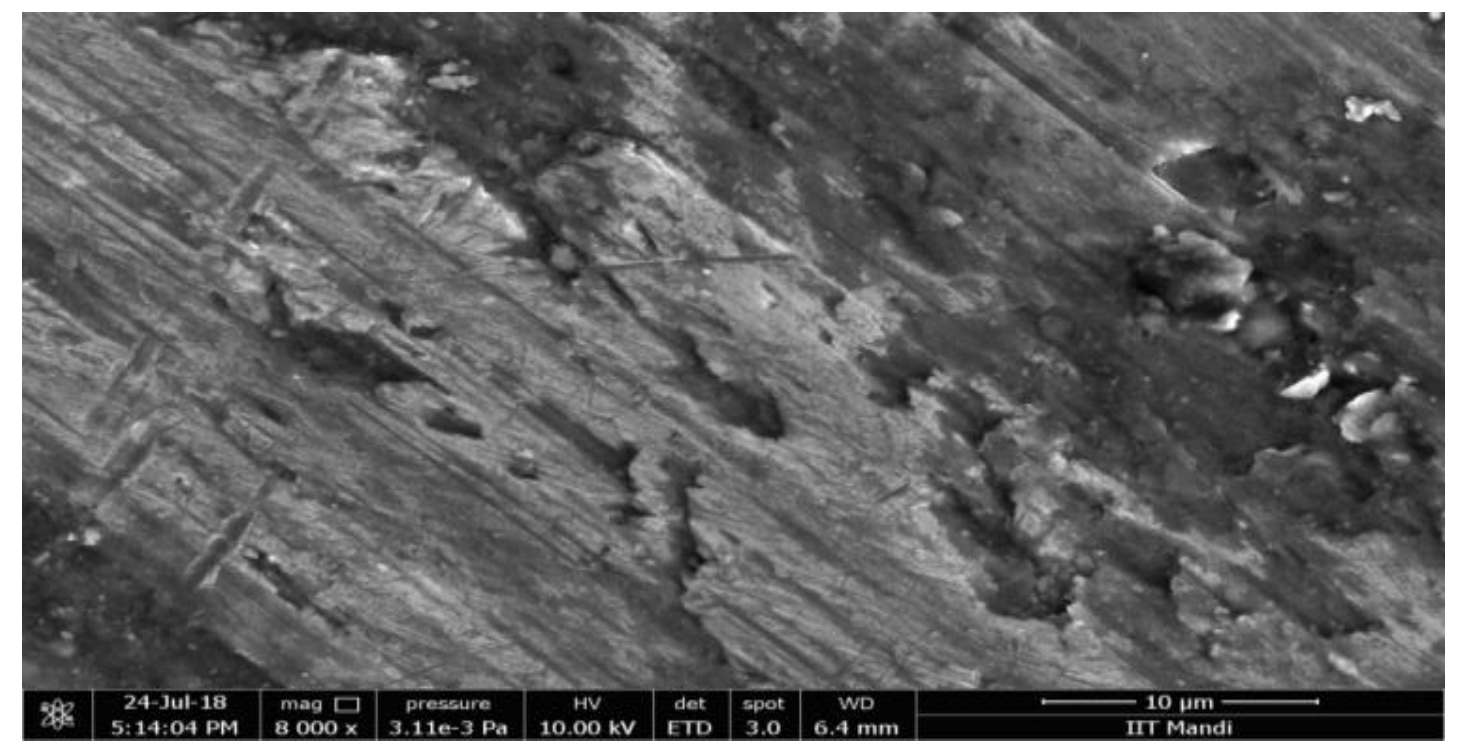

Figure 8. Microscopic representation of Al7075-(5\%)SiC-(1\%)Mg

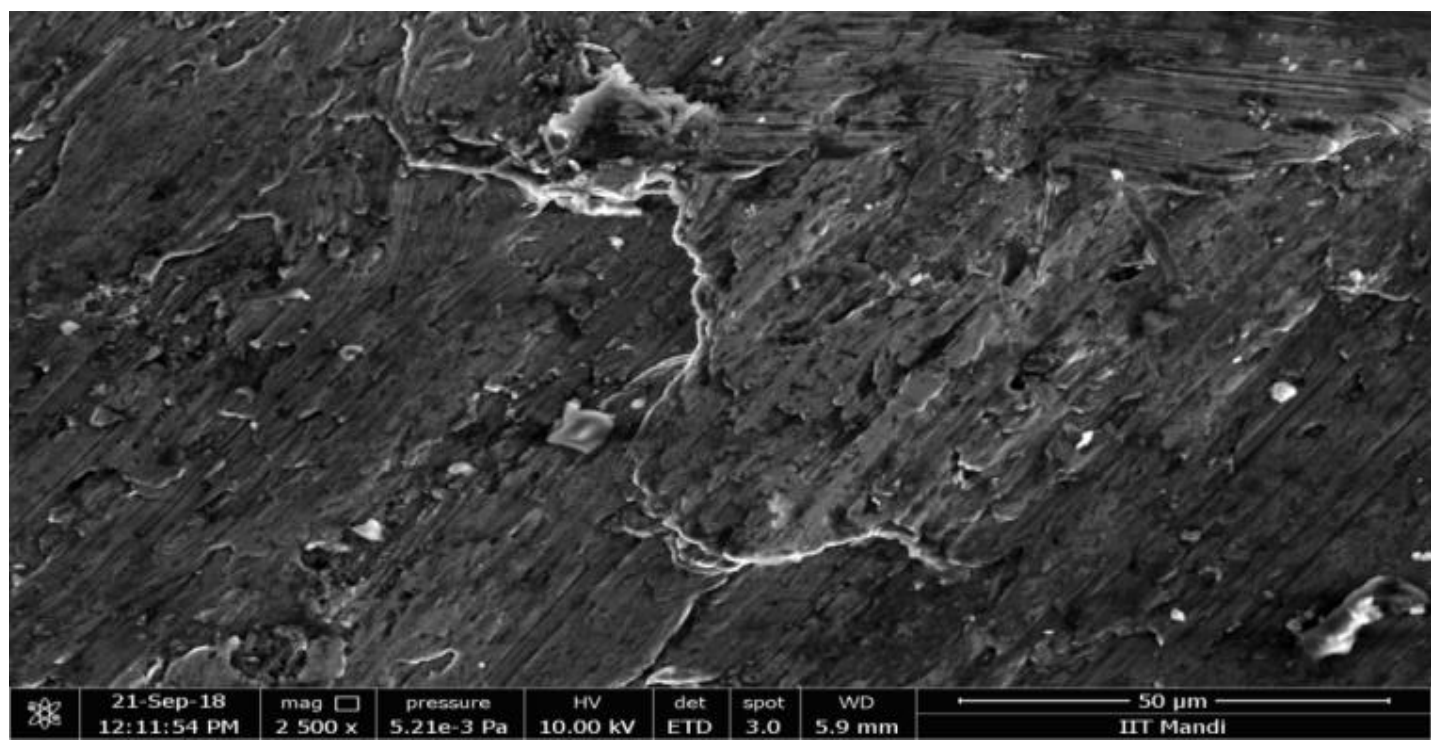

Figure 9. SEM image of Al7075-(10\%)SiC-(1\%)Mg

\subsection{Electrical conductivity}

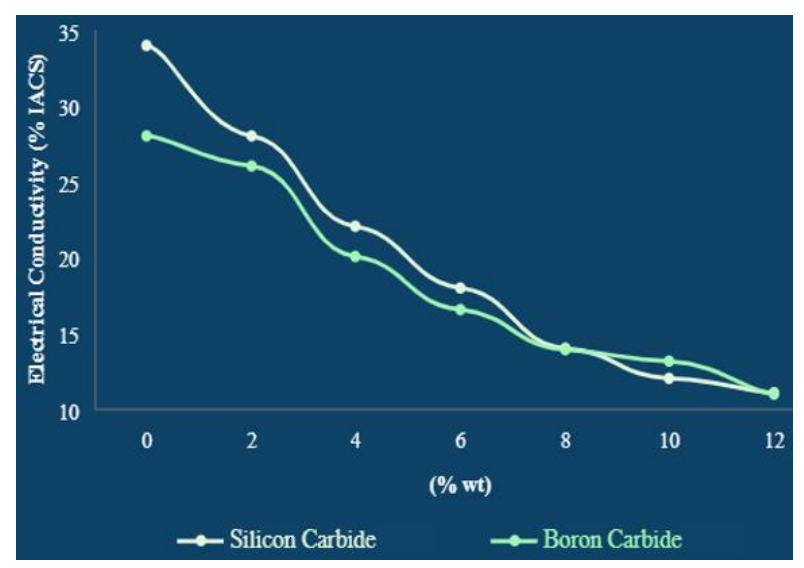

Figure 10. Comparison of electrical conductivity of both the $\mathrm{Al}-\mathrm{SiC}$ and $\mathrm{Al}-\mathrm{B}_{4} \mathrm{C}$ nanocomposites

Figure 10 shows the comparison of the electrical conductivity of both the $\mathrm{Al}-\mathrm{SiC}$ and $\mathrm{Al}-\mathrm{B}_{4} \mathrm{C}$ nanocomposites with different weight percentages. It can be easily depicted from Figure 10 that by increasing the particles of $\mathrm{SiC}$ and $\mathrm{B}_{4} \mathrm{C}$ the electrical conductivity of both the nanocomposites decreases because the particles of reinforcement are contemplated as the origin of the electron dispersion. SiC and $\mathrm{B}_{4} \mathrm{C}$ are a compound semiconductor and when they take the place of $\mathrm{Al}$ the electrical conductivity of Al7075-SiC-Mg and $\mathrm{Al7075}-\mathrm{B}_{4} \mathrm{C}-\mathrm{Mg}$ nanocomposites is reduced [17].

\section{CONCLUSION}

Nano-sized $\mathrm{SiC} / \mathrm{B}_{4} \mathrm{C}$ granules have been assimilated in liquefied pure aluminum with the addition of $\mathrm{Mg}$ as a wetting agent for the production of aluminum matrix composites. The conclusion drawn from this study is as follows:

1. The minimum time for stirring is compulsory for the granules to be correctly blended with the liquefied melt and to form a strong alliance.

2. The development of $\mathrm{Al}_{4} \mathrm{C}_{3}$ helps to create a greater $\mathrm{Al} / \mathrm{SiC}$ bond.

3. The elevated stirring temperature will further lead to a better union of the particle and the melting with the improvised 
dispensation.

4. Cluster of $\mathrm{SiC}$ particulate is seen throughout the samples, it shows uniform mixing of the blend.

5. Moreover, gas pores, coagulation shrinkage, and air space are seen between the clustered particle after stirring, and the porosity can be modified by altering the temperature and period of stirring.

6. In the Hardness test for a load of 50gram, it was observed that the hardness of a sample is determined by the amount of ceramic particulate. Sample with a large amount of ceramic Particulate is much harder than the rest of the samples, whereas the tensile strength and ductility are found out to be determined by the coalition of $\mathrm{Al} / \mathrm{SiC}$ and $\mathrm{Al} / \mathrm{B}_{4} \mathrm{C}$.

7. As the weight percentage of the reinforcement is increased the electrical conductivity of the $\mathrm{Al}$ nanocomposite is decreased.

\section{REFERENCES}

[1] Roy, S., Sharma, S., Sharma S., Shashank, L.M.K, Singh, M. (2017). Review on fabrication of sluminium 7075+ $\mathrm{B}_{4} \mathrm{C}$ composites. International Journal of Advance Research in Science and Engineering, 6(2).

[2] Isfahani, M.J.N., Payami, F., Asadabad, M.A., Shokri, A.A. (2019). Investigation of the effect of boron carbide nanoparticles on the structural, electrical and mechanical properties of $\mathrm{Al}-\mathrm{B}_{4} \mathrm{C}$ nanocomposites. Journal of Alloys and Compounds, 797: 1348-1358. https://doi.org/10.1016/j.jallcom.2019.05.188

[3] Subramaniam, B., Natarajan, B., Kaliyaperumal, B., Jerold, S., Chelladurai, S. (2018). Investigation on mechanical properties of aluminium 7075 - boron carbide - coconut shell fly ash reinforced hybrid metal matrix composites. China Foundary, 15(6): 449-456. ISSN: 2365-9459. https://doi.org/10.1007/s41230-0188105-3

[4] Ali, Z., Umar, M.D., Huq, S.M., Chowdary, M.S., Irfan, M., Ashfaqwali, M. (2019). Characterization of aluminium-7075 reinforced with boron carbide $\left(\mathrm{B}_{4} \mathrm{C}\right)$ synthesized by stir casting. International Journal of Engineering Research \& Technology, 8(6).

[5] Kumar, A.G., Sateesh, J., Kumar, Y.T., Madhusudhan, T. (2016). Properties of Al7075-B $\mathrm{B}_{4} \mathrm{C}$ composite prepared by powder metallurgy route. International Research Journal of Engineering and Technology, 3(7).

[6] Ajagol, P., Anjan, B.N., Marigoudar, R.N., Kumar, P.G.V. (2018). Effect of $\mathrm{SiC}$ reinforcement on microstructure and mechanical properties of aluminum metal matrix composite. Materials Science and Engineering, 376. https://doi.org/10.1088/1757899X/376/1/012057

[7] Nagabhyrava, R., Kota, S., Geda, A., Gudi, S.H. (2017). Investigation of mechanical properties of $\mathrm{AL}$ 7075/SIC/GR hybrid metal matrix composites. International Journal of Mechanical Engineering and Technology, 8(5): 265-269. https://doi.org/10.1016/j.proeng.2014.12.367

[8] Mohal, S. (2017). Microstructural investigation of aluminium-silicon carbide particulate metal matrix composite fabricated by stir casting. International Journal for Innovative Research in Science \& Technology, 3(11).
[9] Pandey, S., Mishra, R., Sasikumar, C. (2014). Fabrication and tribological behavior of aluminium silicon-carbon metal matrix composites. International Journal of Mechanical And Production Engineering, 2(11): 45-48.

[10] Lokesh, K.S., Ummaji, B., Rayappa, G.P.K., Yashavantha, J. (2018). Effect of red mud particles on scratch resistance of aluminum based metal matrix composites. American Journal of Aerospace Engineering (Science Publishing Group), 5(1): 24-29. https://doi.org/10.11648/j.ajae.20180501.14

[11] Cao, F.H., Chen, C., Wang, Z.Y., Muthuramalingam, T., Anbuchezhiyan, G. (2019). Effects of silicon carbide and tungsten carbide in aluminium metal matrix composites. Springer, SN Applied Sciences, 11: 2625-2632. https://doi.org/10.1007/s12633-018-0051-6

[12] Sun, C., Song, M., Wang, Z.W., He, Y.H. (2011). Effect of particle size on the microstructures and mechanical properties of $\mathrm{SiC}$ reinforced pure aluminium composites. J.Mater Eng Perform, 20: 1606-1612. https://doi.org/10.1007/s11665-010-9801-3

[13] Rohit, S., Razal, R.A., Rakshat, B. (2017). Development of magnesium composite material by the method of stir casting for applications in automotive and aerospace industries. COPEN 10, Chennai.

[14] Alaneme, K.K., Ademilua, B.O., Bodunrin, M. (2013). Mechanical properties and corrosion behaviour of aluminium hybrid composites reinforced with silicon carbide and bamboo leaf ash. Tribology in Industry, 35(1): 25-35

[15] Manikandan, E., Balaji, P., Ram, I., Madhan, S.G.G, Velmurugan, K., Venkatachalapathy, V.S.K. (2015). Tribological behavior of aluminium ( $\mathrm{Al}$ ) -magnesium Oxide (MgO) composite. Journal of Material Science and Mechanical Engineering (JMSME), 2: 61-65.

[16] Ghasali, E., Pakseresht, A., Rahbari, A., Eslami-shahed, H., Alizadeh, M., Ebadzadeh, T. (2016). Mechanical properties and microstructure characterization of spark plasma and conventional sintering of Al-SiC-TiC composites. Journal of Alloys and Compounds, 666: 366371. https://doi.org/10.1016/j.jallcom.2016.01.118

[17] Bodunrin, M.O., Alaneme, K.K., ChownLesley, H. (2015). Aluminium matrix hybrid composites: a review of reinforcement philosophies; mechanical, corrosion and tribological characteristics. Journal of Material Research and Technology, 4(4): 434-445. https://doi.org/10.1016/j.jmrt.2015.05.003

[18] Garg, P., Jamwal, A., Kumar, D., Sadasivuni, K.K., Hussain, C.M., Gupta, P. (2019). Advance research progresses in aluminium matrix composites: Manufacturing \& applications. Journal of Material Research and Technology, 8(5): 4924-4939. https://doi.org/10.1016/j.jmrt.2019.06.028

[19] Isfahani, M.J.N., Payami, F., Asadabad, M.A., Shokri, A.A. (2019). Investigation of the effect of boron carbide nanoparticles on the structural, electrical and mechanical properties of $\mathrm{Al}-\mathrm{B}_{4} \mathrm{C}$ nanocomposites. Journal of Alloys and Compounds, 797: 1348-1358. https://doi.org/10.1016/j.jallcom.2019.05.188

[20] Srivastava, A. (2017). Recent advances in metal matrix composites (MMCs): A review. Biomedical Journal of Scientific and Technical Research, 1: 520-522. https://doi.org/10.26717/bjstr.2017.01.000236 